\title{
Revisitando a experiência dos Programas Profissionais da área Ciências da Religião e Teologia/CAPES no Brasil
}

\author{
Reviewing the experience of professional programs \\ in the of Religious Studies and Theology area/CAPES in Brazil
}

\author{
Flávio Senra* \\ Cláudio de Oliveira Ribeiro** \\ Dilaine Soares Sampaio***
}

\begin{abstract}
Resumo
A pesquisa foi desenvolvida considerando-se o debate sobre a especificidade da Pós-Graduação Profissional no âmbito da área Ciências da Religião e Teologia, da Capes (Coordenação de Aperfeiçoamento de Pessoal de Nível Superior), órgão que no Ministério da Educação brasileiro acompanha e avalia o Sistema Nacional de Pós-Graduação (SNPG). O objetivo principal das análises feitas foi construir um panorama de questões em torno do trabalho realizado pelos cursos de mestrados profissionais, incluindo os resultados por eles alcançados, somado a um elenco de aspectos que têm sido identificados como desafiadores para o aprofundamento e aprimoramento dessas práticas bem como as perspectivas que se abrem para essa modalidade de Pós-Graduação no Brasil. Metodologicamente, agrupamos a análise dos dados em dois momentos. O primeiro apresenta, em síntese, um histórico da Pós-Graduação Profissional na área Ciências da Religião e Teologia, com destaque para o conjunto de motivações e objetivos que levaram o Ministério da Educação e a CAPES a implementarem a modalidade de Programas Profissionais no país. Em especial, a reflexão se concentra na visão de uma prática profissional centrada em procedimentos e processos aplicados, visando a solução de problemas que emergem da realidade social. O segundo momento destaca (i) aspectos conceituais sobre a importância da pesquisa aplicada, em especial a tarefa de decolonização a ser desenvolvida no meio acadêmico, (ii) a contribuição das áreas e subáreas da Árvore do Conhecimento, especialmente a "Ciência da Religião Aplicada" e a "Teologia Prática", (iii) o valor da produção técnica e a especificidade dos Trabalhos de Conclusão de Curso (TCC) para a Pós-Graduação Profissional, (iv) as potencialidades e limites da estrutura modular para o oferecimento dos créditos curriculares e (v) o perfil do egresso nesta modalidade.
\end{abstract}

Palavras-chave: Área Ciências da Religião e Teologia. Epistemologia das Ciências da Religião. Ciência da Religião Aplicada. Teologia prática. Pós-graduação Profissional. CAPES.

\begin{abstract}
The research was developed considering the debate on the specificity of the Professional Post-Graduate Studies in the area of Religion and Theology, of Capes (Coordination for the Improvement of Higher-Level Personnel), an organ that in the Brazilian Ministry of Education follows and evaluates the National Post-Graduate Studies System (SNPG). The main objective of the analyses made was to build a panorama of issues around the work done by the professional master courses, including the results achieved by them, added to a list of aspects that have been identified as challenging for the deepening and improvement of these practices as well as the perspectives that are opened for this modality of Graduate Studies in Brazil. Methodologically, we group the data analysis in two moments. The first presents, in summary, a history of Professional Postgraduate Studies in the Sciences of Religion and Theology Area, with emphasis on the set of motivations and objectives that led the Ministry of Education and CAPES to implement the modality of Professional Programs in the country. In particular, the reflection focuses on the vision of a professional practice centered on applied procedures and processes, aiming at the solution of problems that emerge from social reality. The second moment highlights (i) conceptual aspects about the importance of applied research, especially the decolonization task to be developed in the academic environment, (ii) the contribution of the areas and sub-areas of the Knowledge Tree, especially the " "Applied Religious Studies" and the "Practical Theology", (iii) the value of the technical production and the specificity of the Coursework for the Professional Graduation, (iv) the potentialities and limits of the modular structure for the offer of the curricular credits and (v) the profile of the egress in this modality.
\end{abstract}

Keywords: Religious Studies and Theology Area. Epistemology of Religious Studies. Applied Religious Studies. Practical Theology. Professional Graduate Studies. CAPES.

Artigo submetido em 14 de novembro de 2019 e aprovado em 22 de abril de 2020.

\footnotetext{
*Doutor em Filosofia pela Universidad Complutense de Madrid. Professor do PPGCR PUC Minas. País de origem: Brasil. E-mail: flaviosenra@pucminas.br

** Doutor em Teologia pela PUC-Rio. Professor-visitante do PPCIR UFJF. País de origem: Brasil. E-mail: cdeoliveiraribeiro@gmail.com

**** Doutora em Ciência da Religião pela UFJF. Professora da UFPB. País de origem: Brasil. E-mail: dicaufpb@gmail.com
} 


\section{Introdução}

As análises que fazemos a seguir versam sobre a experiência dos mestrados profissionais da área Ciências da Religião e Teologia, da CAPES (Coordenação de Aperfeiçoamento de Pessoal de Nível Superior), órgão que no Ministério da Educação brasileiro acompanha e avalia o Sistema Nacional de Pós-Graduação (SNPG). Esse debate se insere no espectro das discussões sobre epistemologia ${ }^{1}$, em seu recorte político-acadêmico, o que aqui vale tanto para a disciplina Ciência da Religião quanto para a disciplina Teologia.

Outras análises similares foram feitas anteriormente, ora tratando de questões epistemológicas inerentes à área, ora de questões e contextos históricos. ${ }^{2}$ O que se pretende com este artigo é seguir colaborando com a reflexão em curso.

A área Ciências da Religião e Teologia conta, considerando o final de 2019, com quatro programas de pós-graduação na modalidade profissional, sendo três de Teologia e um de Ciências da Religião. Os mestrados profissionais de Teologia são oferecidos nas Faculdades EST (EST), em São Leopoldo/RS, que é o mais antigo, recomendado em 2002, nas Faculdades Batistas do Paraná (FABAPAR), em Curitiba/PR, recomendado em 2011 e na Faculdade Teológica SulAmericana, em Londrina/PR, recomendado em 2019. Na Faculdade Unida (UNIDA), em Vitória/ES, é oferecido o curso de Mestrado Profissional em Ciências das Religiões, recomendado em 2010. Mesmo representando um percentual próximo a 20\% dos programas da área, sua capacidade de formação é significativa.

O nosso objetivo nesta análise é apresentar um panorama de questões que têm sido identificadas como desafiadoras para o aprofundamento e aprimoramento dessa modalidade de programas de pós-graduação no Brasil.

\footnotetext{
${ }^{1}$ Considerando a totalidade da área com os seus atuais 21 programas, tanto os de modalidade acadêmica (17) quanto profissional (4), há variações em relação à nomenclatura dos cursos. A CAPES, seguindo a proposição feita pela Associação Nacional de Pós-Graduação e Pesquisa em Teologia e Ciências da Religião (ANPTECRE), utiliza a expressão "Ciências da Religião e Teologia" para designar a área de avaliação. Acompanharemos aqui essa nomenclatura oficial. Para uma visão geral sobre esse debate conceitual veja o texto de Villas Boas (2018) e Flávio Senra (2016). Veja-se ainda, a despeito do debate epistemológico na área as contribuições de Villas Boas (2020) e de Senra, Campos e Almeida (2020).

${ }^{2}$ Veja-se em Rocha; Ribeiro (2019), Mesquiatti; Brotto (2018), Senra (2017) Streck; Almeida (2017).
} 


\section{Aspectos históricos dos Programas Profissionais da área Ciências da Religião e Teologia/CAPES}

Em 22 de junho de 2009, através da Portaria Normativa $\mathrm{n}^{0}$ 7, o Ministério da Educação (MEC) regulamentava a modalidade de Mestrado Profissional no âmbito do Sistema Nacional de Pós-graduação (SNPG), sob responsabilidade da Coordenação de Aperfeiçoamento de Pessoal de Nível Superior (CAPES). 3

A área Ciências da Religião e Teologia surgiu da separação entre as duas subáreas da antiga Área Filosofia/Teologia.4 O documento que norteava o trabalho da antiga área Filosofia/Teologia: Subcomissão Teologia oferecia uma orientação geral para a criação dos mestrados profissionais que, embora válida e relevante para a atualidade, se constituía insuficiente, por ser pouco detalhada e por não apresentar orientações para aspectos importantes da totalidade da dinâmica acadêmica em nível de Pós-Graduação, sobretudo considerando o aspecto inovador que a proposição da modalidade profissional possui.

Desde agosto de 2015, quando na CAPES se organizou um seminário de acompanhamento com programas de todas as áreas, a área sinalizou para a necessidade de se discutir mais profundamente os cursos de mestrado profissional. De modo particular evidenciou-se como tarefa a maior e melhor discussão sobre o seu perfil e a sua especificidade na formação de mestres e mestras. A coordenação da área, naquela época formada pelos professores Flávio Senra, coordenador, e Remí Klein5, coordenador adjunto para mestrados profissionais, passaram a trabalhar, no ano de 2015, no aperfeiçoamento do Documento para Apresentação de propostas para cursos novos (APCN). A estratégia era sinalizar para novos

\footnotetext{
${ }^{3}$ A Portaria Normativa no 7/2009 foi revogada pela Portaria Normativa no 17/2009. Cf.: MEC - 2009a e 2009b. As motivações e objetivos previstos na primeira normatização ficaram mantidos. A Portaria mais recente a legislar sobre os Programas Profissionais, inclui a possibilidade de criação de cursos de Doutorado nesta modalidade. Trata-se da Portaria no 389/2017. Cf.: MEC -, 2017. Embora com redação mais sucinta, os objetivos previstos igualmente se mantêm como diretrizes para os programas profissionais do SNPG.

${ }^{4}$ A criação da área se deu pela Portaria 174/2016, publicada no DOU de 13 de outubro de 2016, com o nome Teologia. Cf.: CAPES, 2016. A nomenclatura foi objeto de redesignação, conforme proposta encaminhada pela Associação Nacional de Pós-graduação $e$ Pesquisa em Teologia e Ciências da Religião (ANPTECRE), e passou a se chamar Ciências da Religião e Teologia, de acordo com a Resolução no 1, de 4 de abril de 2017, publicada no Boletim de Serviço/CAPES - Edição Especial no 1 - abril/2017. Cf.: CAPES, 2017a.

${ }^{5}$ Falecido em 2020, o Prof. Remi Klein é um nome a ser exaltado na história da área de Ciências da Religião e Teologia, em virtude não só de sua contribuição como coordenador adjunto, mas de todo o trabalho que desenvolveu na questão do Ensino Religioso.
} 
cursos um perfil desejado para o interno da área, algo que se replicaria nas avaliações quadrienais seguintes e no Documento da Área que orienta o trabalho e a avaliação dos cursos já recomendados e reconhecidos. O objetivo, como se tornou público, era oferecer uma orientação mais precisa para os programas profissionais, algo que até então, como já referido, parecia ser insuficiente. Por um bom período, os programas profissionais da área, desde o mais antigo ao mais recente, funcionaram com uma orientação básica, tal como se pode verificar acima. Esse foi o diagnóstico da Capes em reuniões e visitas que se fizeram realizar sob a motivação de se aperfeiçoar o entendimento sobre os Programas Profissionais na área.

Esse processo teve vários desdobramentos. Em junho de 2017, na Universidade Metodista de São Paulo (UMESP), a coordenação de Área e a coordenadora adjunta para Mestrados Profissionais, naquela época a Profa. Sandra Duarte de Souza, se reuniram com as coordenações dos três programas existentes na ocasião. Foi discutido o perfil dos mestrados profissionais da área Ciências da Religião e Teologia com apresentação da proposta de cada um dos programas. Também se discutiu o Documento de área (CAPES, 2019a) com o objetivo de se produzir indicações e orientações mais objetivas para a consolidação da modalidade no interno da comunidade.

Posteriormente, dentro do processo regulamentar da CAPES para todas as áreas, foi feita no primeiro semestre de 2019, em diálogo com a comunidade acadêmica da área Ciências da Religião e Teologia, uma atualização do Documento orientador de APCN (CAPES, 2019b). Isto possibilitou melhor identificação dos objetivos dos mestrados profissionais, o que, embora seja um documento balizador das novas propostas, contribui para o aprimoramento das práticas em curso. Voltaremos a ele em nossa análise.

Paralelamente a esse processo, a CAPES estabeleceu em seus órgãos colegiados internos o debate sobre a implantação dos cursos de Doutorado Profissional. 
Diante desse quadro, a área considerou importante realizar o I Seminário sobre Mestrados Profissionais. O evento, realizado nas dependências das Faculdades EST, em São Leopoldo/RS, em março de 2019, foi coordenado pelo Prof. Claudio de Oliveira Ribeiro, Coordenador dos Programas Profissionais da área, e teve a participação de representantes docentes dos três programas profissionais em funcionamento na época, suas coordenações e representação da Associação Nacional de Pesquisa e Pós-Graduação em Teologia e Ciências da Religião (ANPTECRE). Os objetivos foram: i) socializar as práticas exitosas e os limites dos cursos de mestrado profissional na área de Ciências da Religião e Teologia, ii) aprofundar a análise do Documento de área (CAPES, 2019a) que rege os processos avaliativos, dentro do contexto histórico em que se desenvolveu a PósGraduação Profissional, e, iii) realçar a especificidade profissional da PósGraduação Profissional, a importância da experiência e produção técnica do corpo docente, da interdisciplinaridade das pesquisas e produções docente e discente, e da diversidade quanto à área de formação dos/as docentes.

Das reflexões feitas, levando em consideração a experiência de trabalho dos Programas ao longo dos anos, as necessidades da sociedade brasileira e os desafios que ela nos apresenta, destacamos a proposta da ANPTECRE de se ter um grupo de trabalho para se debruçar sobre pontos importantes para a Pós-Graduação Profissional ${ }^{6}$. Pensando em perspectivas para a consolidação da Pós-Graduação Profissional na área Ciências da Religião e Teologia, foram enfatizados os seguintes aspectos: i) o valor da pesquisa aplicada nos mestrados profissionais (em especial a compreensão do que é a pesquisa aplicada; os níveis de aplicabilidade possíveis e desejados, a diferença entre pesquisa contextualizada e pesquisa aplicada, o debate em tornos das atividades eclesiais e/ou religiosas como dimensão profissional, etc.); ii) a importância da produção técnica para a Pós-Graduação Profissional (definições sobre a natureza da produção técnica correspondente, sua qualificação, as formas adequadas de registro, etc.); iii) o destaque para a Árvore do Conhecimento, sobretudo as subáreas "Ciência da Religião Aplicada" e "Teologia

\footnotetext{
${ }^{6}$ O Prof. Julio Cezar Adam, das Faculdades EST, Membro do Conselho Científico da ANPTECRE, foi indicado para coordenar esse grupo de trabalho. A indicação foi aprovada na Assembleia da Associação, ocorrida em setembro de 2019, na Pontifícia Universidade Católica do Rio de Janeiro (PUC-Rio), por ocasião do VII Congresso Nacional da ANPTECRE.
} 
Prática”, e a necessidade de atualização dos temas-correlatos de todos as subáreas; iv) os formatos variados dos Trabalhos Finais dos cursos, e a possiblidade deles em traduzir a dimensão profissional da Pós-Graduação; v) a estrutura modular de cursos intensivos utilizada pelos Programas (justificativas, vantagens e limites), e, vi) a reflexão permanente sobre o perfil dos egressos, como elemento elucidador das propostas dos cursos.

Esses elementos precisam ser ampliados e aprofundados pelos programas, pelos fóruns de acompanhamento e de avaliação e pelos demais setores e associações que interagem a área. Na sequência, veremos com maior atenção alguns desses pontos, conscientes de que se trata de uma tarefa inconclusa, permanente e que deve ser cumprida coletivamente, com o envolvimento, participação ativa e corresponsabilidade dos vários segmentos envolvidos e interessados nesse processo de consolidação da experiência de pós-graduação profissional na área de Ciências da Religião e Teologia.

\section{Perspectivas para a consolidação}

Entre os diferentes aspectos que desafiam e mobilizam as reflexões e debates em torno da pós-graduação profissional na área de Ciências da Religião e Teologia, destacaremos: aspectos conceituais sobre i) a importância e alguns desafios da pesquisa aplicada, ii) a contribuição da árvore do conhecimento, iii) o valor da produção técnica a iv) especificidade dos trabalhos de conclusão de curso (TCC), v) as potencialidades e limites da estrutura modular para o oferecimento dos créditos curriculares, e vi) o perfil do egresso.

\subsection{A importância e os desafios da pesquisa aplicada}

Há uma série de esforços para pensar sobre os desafios do processo de consolidação da área, desde a sua autonomia. Em publicação recente feita por Sampaio (2019), intitulada Ciências da Religião e Teologia como área autônoma: reconfiguração do debate epistemológico, novos desafios e perspectivas para o 
estudo das (não) religiões e da(s) espiritualidade(s), há a proposição, enquanto um exercício de sistematização das perspectivas, de três movimentos que na prática são concomitantes:

um primeiro, seria direcionado ao âmbito da casa, endógeno, de dentro para dentro da área, refletindo acerca da necessidade de pensarmos uma nova perspectiva de diálogo entre Ciências da Religião e Teologia que possa contribuir tanto para a consolidação da área quanto para o fortalecimento da especificidade desse campo de saber. Um segundo, que denomino de exo-endógeno, seria direcionado de fora para dentro, quando apontarei para a necessidade de aprofundarmos nossos movimentos antropofágicos em relação às perspectivas teóricometodológicas das áreas afins. E um terceiro, de caráter mais exógeno, ou seja, direcionado de dentro da área para fora, na medida em que haverá cada vez mais a necessidade de nos colocarmos perante nossos pares, demonstrando que a área de Ciências da Religião e Teologia tem as suas especificidades e oferece, portanto, um olhar distinto (SAMPAIO, 2019, p. 892).

Deve-se estar alerta para o caráter performático desses movimentos propostos bem como para o seu entrelaçamento inevitável. O texto acima destacado procura pensar especificamente o lugar da Ciência da Religião Aplicada e da Teologia Prática no âmbito da agenda mais ampla proposta acima.

Dentre as perspectivas apontadas no âmbito do movimento endógeno, e nesse caso já a caminho do movimento exo-endógeno e entrelaçado a ele, vale destacar a necessidade, para a consolidação da área, de sua decolonização7.

A área de Ciências da Religião e Teologia dedica a maior parte de seus estudos ao cristianismo, religião hegemônica em nosso país. Tal constatação pode ser feita consultando as áreas de concentração, linhas e projetos de pesquisa disponibilizados nos sites dos vinte e um programas que integram a área 44 - Ciências da Religião e Teologia na CAPES. As religiões africanas, afro-brasileiras e indígenas ainda são pouco estudadas na área. Há apenas cinco programas, dentre os vinte e um da área 44, que possuem docentes que se dedicam ao estudo das religiões afro-brasileiras, ofertando, portanto, disciplinas e orientando discentes de mestrado e/ou doutorado. Já as religiões indígenas são ainda menos estudadas, havendo apenas dois programas na área com docentes dedicados ao tema. Dar mais atenção a outras religiões não hegemônicas, historicamente invisibilizadas, por si só, não resolveria a questão, pois há a armadilha de tratar essas religiões reificando as mesmas estruturas de opressão às quais

\footnotetext{
${ }^{7}$ Optamos pelo uso do termo decolonização e decolonialidade seguindo os estudos de Aníbal Quijano (2010), que implica o enfrentamento da "colonialidade do poder". O tema é bastante vasto e se conecta aos chamados estudos pós-coloniais, de(s)coloniais, de-coloniais ou ainda estudos subalternos. Embora a discussão ainda careça de grande aprofundamento nas Ciências da Religião e Teologia, recomendamos o texto de Lauri Wirth (2013), intitulado Religião e epistemologias pós-coloniais para uma introdução ao tema.
} 
foram submetidas, ou seja, sob a perspectiva da colonialidade. (...) Isto podemos aprender com as discussões em torno do giro decolonial ou ainda as discussões acerca das epistemologias do sul (NUNES, 2010). O que se considera importante é que os estudos das religiões afro-indígenas são capazes de conduzir aquele/a que o faz para a audição de outras epistemes, que se fazem presentes naquelas vivências religiosas e assim a área terá condições de contribuir para o fim do epistemicídio ${ }^{8}$ (SANTOS; MENESES, 2010) até então praticado pelo universo acadêmico, marcado pelo eurocentrismo e pelo ocidentalismo (SAMPAIO, 2019, p. 902-903).

Já no âmbito do movimento exógeno, gostaríamos de enfatizar, por exemplo,

o compromisso e a responsabilidade da área com a manutenção e o fortalecimento da democracia e dos direitos humanos num contexto nacional de instrumentalização da religião para o desenvolvimento de políticas opressoras e supressoras de direitos. Este movimento exógeno deve incluir uma atuação e uma forte reflexão do papel da área no atual contexto, no sentido de pensar e mostrar o que cientistas da religião e teólogos têm a contribuir para a sociedade. (SAMPAIO, 2019, p. 904905).

Destacamos, portanto, que a atenção devida a decolonização nas pesquisas desenvolvidas na área, a contribuição para a superação dos epistemicídios, o compromisso e a responsabilidade da área com a manutenção e o fortalecimento da democracia e dos direitos humanos na sociedade são tarefas que as subáreas de Ciência da Religião Aplicada e de Teologia Prática podem desenvolver de modo pleno.

Nessa direção, Tworuschka nos mostra que os termos "ciência da religião engajada", "ciência da religião aplicada", ou ainda "ciência da religião baseada em aplicação", embora expressem conceitos distintos, partilham de uma ideia comum: “a conversão da ciência da religião em uma ciência útil a serviço da solução de problemas comuns causados, em parte, pela(s) religião(ões)” (TWORUSCHKA,

\footnotetext{
${ }^{8}$ Boaventura de Souza Santos entende como epistemicídio o processo de "supressão dos conhecimentos locais perpetrada por um conhecimento alienígena". Assim, "sob o pretexto da 'missão colonizadora', o projeto da colonização procurou homogeneizar o mundo, obliterando as diferenças culturais (SANTOS; MENESES, 2010, p. 16-17). Com isso, desperdiçou-se muita experiência social e reduziu-se a diversidade epistemológica, cultural e política do mundo. Na medida em que sobreviveram, essas experiências e essa diversidade foram submetidas à norma epistemológica dominante (...)" (SANTOS; MENESES, 2010, p. 16-17). A partir do Boaventura Souza Santos, Sueli Carneiro irá tratar, em sua tese de doutoramento, a questão do epistemicídio, conectando-o ao dispositivo de racialidade/biopoder, fazendo-o de modo aprofundado no capítulo três de seu trabalho (CARNEIRO, 2005). (SAMPAIO, 2019, p. 903).
} 
2018, p. 31)9. O debate traz, como pano de fundo, a forte questão da "neutralidade" da ciência ou ainda de sua "imparcialidade", como bem ponderou o referido autor (Cf. TWORUSCHKA, 2018). Outros autores, como Hanegraaf, revelam sua dificuldade em pensar uma pesquisa "desinteressada" e "imparcial", e que mais produtivo seria investir na crítica e na autocrítica da pesquisa acadêmica:

Pesquisas desinteressadas nas ciências humanas ou são uma pretensão ou simplesmente produzem aquilo que é de se esperar, ou seja, uma investigação desinteressante; e até mesmo se alguém fosse defendê-las, suas motivações pessoais para assim fazer poderiam, elas próprias, ser objeto de investigação. Em vez de uma demanda inútil pela imparcialidade da pesquisa, o que precisa (continuamente) ser defendida na pesquisa acadêmica é a prática fundamental da crítica (incluindo, crucialmente, a autocrítica) no que diz respeito à forma como tais desvios podem, conscientemente ou não, influenciar a pesquisa (HANEGRAAF, [1999] 2017, p. 234).

No campo teológico, o caráter propositivo, prático e de inserção social possui forte destaque. No Documento de área (CAPES, 2019a), tal perspectiva se encontra explícita no elenco de habilidades do egresso pós-graduado em Teologia para que seja “capaz de desenvolver uma teologia da práxis” (CAPES, 2019a, p. 4-5). Tal visão possui um longo histórico que remonta as décadas de 1960 e 70, envolvendo setores eclesiais e acadêmicos. Ela está associada, direta e indiretamente, às bases da Teologia Latino-Americana da Libertação. As análises mais apuradas têm mostrado que está diante da teologia latino-americana, em suas variadas expressões, a tarefa de aprofundar os seus esforços e de refletir sobre as demandas que a sociedade apresenta e que recaem sobre o quadro da diversidade religiosa e cultural, seja o que está em torno das questões do método teológico, do quadro religioso plural ou de questões de natureza antropológica. Essas últimas podem ser exemplificadas na capacidade de alteridade ecumênica, nas formas autênticas de espiritualidades integradoras, inclusivas e ecológicas, e no valor da corporeidade e da sexualidade na reflexão teológica e nas ações concretas de afirmação da vida (RIBEIRO, 2016).

\footnotetext{
${ }^{9}$ Os pioneiros da disciplina traziam essa preocupação, como já bem demonstrou a tese de Matheus Costa (2019), defendida na PUC SP, que recupera bem as controvérsias em torno do que seria a prática da Ciência da Religião Aplicada ou da Ciência Prática da Religião, termo preferido por Udo Tworuschka (2013).
} 
Em alguns ambientes, nesta mesma perspectiva, tem se privilegiado a expressão “teologia pública”. Para Rudolf von Sinner (2012, p. 20) trata-se de "algo que serve para uma reflexão apurada sobre o papel da religião no mundo contemporâneo, na política, na sociedade, na academia, como reflexão construtiva, crítica e autocrítica das próprias igrejas, comunicando-se com outros saberes e com o mundo real”. Nessa direção, Faustino Teixeira mostra que em várias partes do globo e também no Brasil há novos espaços teológicos nas universidades e instituições de pós-graduação, com "propriedade científica", inovação metodológica e perspectivas interdisciplinares. Isto requer liberdade institucional em relação às igrejas. Estas

[...] novas e provocadoras reflexões de uma Teologia Pública reconfiguram o complexo debate envolvendo a Ciência da Religião e a Teologia. Resistências quanto à presença da Teologia no âmbito da universidade, entendida como disciplina acadêmica, começam a se arrefecer, tendo em vista novos delineamentos proporcionados pela reflexão teológica (TEIXEIRA, 2013, p. 175).

Diante do exposto vale recordarmos os temas correlatos da nossa árvore do conhecimento. Os da Ciência da Religião aplicada são: Religião e espaço público, política, ética, saúde, ecologia, culturas; temas associados à diversidade, respeito e tolerância; diálogo inter-religioso; educação e religião, e os da Teologia Prática são: Psicologia pastoral, teologia e saúde, ecoteologia, fé e política, homilética, relação entre teologia/culto/práxis, missão e inculturação, inclusão e direitos humanos, teologia e sociedade, ação, experiência e conhecimento prático, educação na respectiva tradição. Embora os temas correlatos não esgotem as possibilidades de trabalho, a questão da diversidade e do respeito aos direitos e culturas subalternas estão presentes. É difícil pensarmos uma Ciência da Religião Aplicada e uma Teologia Prática que não sejam também comprometidas com esta questão marcante na sociedade atual. Nesse aspecto, não temos um problema maior ou tão distinto das outras áreas do conhecimento. A Antropologia, por exemplo, especialmente se pensarmos as especificidades de uma Antropologia de Políticas Públicas, ou na elaboração de laudos antropológicos que fazem parte do seu metiê, se defronta com as questões da aplicabilidade da pesquisa. Questões similares encontramos em outras áreas do conhecimento. 
Para que se possa compreender o potencial da pesquisa aplicada na área, passamos agora a pensar os seguintes temas-pautas: intolerância religiosa, racismo religioso e o epistemicídio, os quais percebemos como relevantes para a aplicabilidade profissional das pesquisas. E nesse âmbito, vamos tomar o caso das religiões de matrizes africanas como exemplo, devido ao histórico processo de perseguição que sofrem no Brasil.

Não faltam trabalhos em nossa área e nas áreas afins, como nas Ciências Sociais, que discutam a temática da intolerância religiosa. Todavia, no que tange ao racismo religioso e ao epistemicídio, até onde pudemos levantar, a área de Ciências da Religião e Teologia está bastante aquém das áreas afins, especialmente da Antropologia, que tem se dedicado fortemente ao tema.

O debate conceitual que envolve a intolerância religiosa e o racismo religioso é bastante complexo. Muitos autores, como Flor do Nascimento (2016, 2017), por exemplo, consideram que o uso do termo intolerância religiosa ${ }^{10}$ não é suficiente para compreender a violência impetrada contra as religiões afro-brasileiras em nosso país, uma vez que ela esconde uma questão principal que é a do racismo estrutural ${ }^{11}$. Dessa forma, a intolerância em relação às religiões afro-brasileiras não se dá simplesmente por uma questão religiosa, mas pela intersecção entre a questão racial e religiosa, levando ao uso do conceito de racismo religioso. Entendemos que as noções podem se manter complementares, de modo que o racismo religioso não precisa necessariamente substituir a "intolerância religiosa", mas podem e devem entrar em diálogo. Outro aspecto importante do debate é como pensar a intolerância religiosa como um problema público, superando o reducionismo que pensa a partir do par intolerância-tolerância. ${ }^{12}$

\footnotetext{
${ }^{10}$ Os dados mais atuais do Disque 100 revelam que mais de $70 \%$ das denúncias envolvendo intolerância religiosa estão vinculadas às religiões afro-brasileiras como vítimas (MINISTÉRIO DA JUSTIÇA E CIDADANIA, 2016). E os números cresceram muito após 2016 (MINISTÉRIO DA MULHER, DA FAMÍLIA E DOS DIREITOS HUMANOS, 2019). Cotidianamente terreiros são invadidos e a maioria dos casos fica sem solução.

${ }^{11}$ Para melhor compreensão dos conceitos sugerimos a recente obra de Silvio Almeida (ALMEIDA, 2019).

${ }^{12}$ Para isso veja as indicações de Roberta de Mello Corrêa e de Rosiane Rodrigues de Almeida (CORRÊA, ALMEIDA, 2017) e de Ana Paula Miranda (MIRANDA, 2014).
} 
Considerando os temas correlatos às subáreas da árvore do conhecimento, é facilmente perceptível a necessidade de atenção a essa pauta, e o papel delas aplicada ao Ensino Religioso é fundamental. Todavia, pensar somente os problemas no âmbito dos espaços escolares e, particularmente, às questões controversas do Ensino Religioso em si não resolvem. É preciso pensar o papel da área como um todo. Se os epistemicídios continuarem a serem reforçados, sem sequer haver uma reflexão sobre do que se trata e, mais importante ainda, quais as formas de superá-lo, entendemos que a subárea Ciência da Religião aplicada ao Ensino Religioso em particular e ao debate sobre educação e religião em sentido mais amplo, não se mostrará eficaz, pois a colonialidade domina não só os currículos escolares, mas também os acadêmicos.

A academia foi e ainda é um espaço de reprodução desses epistemicídios. $\mathrm{Na}$ academia brasileira, a produção intelectual ainda se mantém focada em perspectivas eurocentradas, o que pode ser visto facilmente nas bibliografias de teses, dissertações e trabalhos de conclusão de curso. É preciso, urgentemente, sem mais demora, que mudemos as rotas, é preciso ações afirmativas também na produção intelectual, e nesse âmbito, consideramos ainda mais urgente o debruçar, não somente, mas tomamos como um exemplo, sobre os trabalhos das intelectuais e feministas negras ${ }^{13}$. Outras epistemes precisam ser incorporadas, pois a superação do epistemicídio é certamente um dos caminhos para a superação da intolerância religiosa e do racismo religioso. Vale ressaltar que a superação do epistemicídio não se dará sem a leitura e uso de autores e autoras de grupos historicamente excluídos ou marginalizados e que têm ampliado muito a publicação de trabalhos. Referimo-nos, também como exemplo, à produção intelectual indígena e à produção LGBTQI+.

\footnotetext{
${ }^{13}$ Embora pudéssemos citar muitos outros nomes, a título de exemplificação e mesclando autoras de épocas distintas, consideramos que Sueli Carneiro (2016), Angela Davis (2016), Djamila Ribeiro (2017), Carla Akotirene (2019), Joyce Berth (2019), dentre muitas outras feministas e intelectuais negras precisam ser lidas, ouvidas e utilizadas em nossos trabalhos, independentemente de nossas pesquisas serem sobre gênero e raça, pois diversos conceitos trabalhados por elas podem ser extremamente produtivos para os estudos que desenvolvemos na área.
} 
Consideramos que a reflexão sobre a importância e os desafios da pesquisa aplicada pode ser localizada no âmbito de uma agenda maior já pensada como perspectiva para a nossa jovem área autônoma. Os temas-pautas utilizados como exemplo de questões que precisam ocupar a agenda da área 44 depende de um grande investimento em sua decolonização, ou toda a empreitada ficará comprometida. $\mathrm{O}$ aprofundamento dos debates em torno da árvore do conhecimento e em torno de aspectos estruturais da Pós-Graduação Profissional é necessário e urgente. Nossas disciplinas e até mesmo nossos currículos precisam enfrentar esse desafio ou não haverá aplicabilidade daquilo que não se conhece com profundidade.

\subsection{A contribuição da árvore do conhecimento ${ }^{14}$}

Conectadas com os desafios da pesquisa aplicada estão as reflexões em torno da árvore do conhecimento. Segundo as diretrizes vigentes da área Ciências da Religião e Teologia, as oito subáreas que compõem a atual árvore do conhecimento revelam que a pesquisa que se desenvolve nesta área tem um perfil interdisciplinar. ${ }^{15}$ Aliás, esta é uma das grandes tendências do debate acadêmico atual. Diversas áreas de conhecimento, em especial, as que formam disciplinas caracterizadas pela conjunção entre área + da religião, em particular as tocantes à subárea Ciências Empíricas da Religião, atestam esta composição interdisciplinar a enriquecer os estudos na área.

No tocante aos Programas Profissionais, o valor da visão de interdisciplinaridade se mantém igualmente relevante. Além disso, o que temos realçado em nossas análises é a importância da árvore do conhecimento para a

\footnotetext{
${ }^{14}$ A área Ciências da Religião e Teologia reconhece oito subáreas, a saber: Ciência da religião aplicada; Ciências da linguagem religiosa; Ciências empíricas da religião; Epistemologia das ciências da religião; História das teologias e religiões; Teologia fundamentalsistemática; Teologia prática; Tradições e escrituras sagradas. Estas oito subáreas foram aprovadas em maio de 2012, em Assembleia da Associação Nacional Pós-graduação e Pesquisa em Teologia e Ciências da Religião (ANPTECRE). Um detalhamento sobre esse processo pode ser acessado em SENRA (2015).

${ }^{15}$ Veja-se em CAMURÇA (2008); FERREIRA; SENRA (2012) e RIBEIRO (2019). Para o debate sobre a interdisciplinaridade, veja-se PHILIPPI JÚNIOR; SILVA NETO (2011).
} 
pós-graduação profissional no sentido de conferir possibilidades de melhor identificação de sua especificidade. Consideramos que duas das subáreas da atual árvore do conhecimento, a saber, Ciência da Religião Aplicada e Teologia Prática, oferecem mais adequadamente essas condições. A atenção às ementas que norteiam essas duas subáreas possibilita melhor compreensão do perfil desejado para a Pós-Graduação Profissional.

No caso da subárea de Ciência da Religião Aplicada, os temas correlatos identificados no Documento de área (CAPES, 2019a), como já mencionados, são: "religião (...) e espaço público, política, ética, saúde, ecologia, culturas; temas associados à diversidade, respeito e tolerância; diálogo inter-religioso; educação e religião.” No caso da subárea Teologia Prática, os temas correlatos identificados no mesmo documento são: "Psicologia pastoral, teologia e saúde, ecoteologia, fé e política, homilética, relação entre teologia/culto/práxis, missão e inculturação, inclusão e direitos humanos, teologia e sociedade, ação, experiência e conhecimento prático, educação na respectiva tradição”.

É fundamental que os temas correlatos de todas as áreas sejam revistos e atualizados periodicamente. Isto deve ser feito a partir da reflexão permanente dos Programas em relação aos desafios conceituais e práticos que enfrentam dentro do quadro sociocultural e religioso nacional e internacional e as respostas possíveis que têm sido dadas nas diferentes atividades acadêmicas que desenvolvem.

Os programas profissionais da área apresentam as seguintes áreas de concentração e linhas de atuação e projetos de pesquisa. 
Quadro 1 - Mestrados Profissionais da área Ciências da Religião e Teologia/CAPES

\begin{tabular}{|c|c|c|}
\hline PROGRAMA & $\begin{array}{c}\text { ÁREA (S) DE } \\
\text { CONCENTRAÇÃO }\end{array}$ & LINHAS DE ATUAÇÃO \\
\hline \multirow[t]{2}{*}{ FACULDADES EST } & Teologia e Sociedade & $\begin{array}{l}\text { 1. Dimensões do cuidado e } \\
\text { práticas sociais. 2. Teologia } \\
\text { na América Latina (Ênfase: } \\
\text { Teologia Libertadora). } 3 \text {. } \\
\text { Teologia na América Latina } \\
\text { (Ênfase: Teologia } \\
\text { Pentecostal). }\end{array}$ \\
\hline & Religião e Educação & $\begin{array}{l}\text { 1. Ética e gestão. 2. Gênero, } \\
\text { feminismos e diversidade. } \\
\text { 3. Educação comunitária } \\
\text { com infância e juventude. } \\
\text { 4. Leitura e ensino da } \\
\text { Bíblia. }\end{array}$ \\
\hline
\end{tabular}

FACULDADE UNIDA

FABAPAR

Teologia Prática
1. Religião e Espaço Público. 2. Ensino religioso escolar.

\begin{tabular}{cll}
\hline FABAPAR & Teologia Prática & $\begin{array}{l}\text { 1. Releitura de textos e } \\
\text { contextos bíblicos. 2. } \\
\text { Teologia e Práxis Pastoral e } \\
\text { Comunitária. } \\
\text { Espiritualidade, educação e }\end{array}$ \\
& $\begin{array}{l}\text { docência nos processos } \\
\text { formativos. }\end{array}$ \\
\hline SUL-AMERICANA & Teologia Prática & $\begin{array}{l}\text { 1. Práxis Pastoral Urbana. } \\
\text { Teologia \& Espaço } \\
\text { Público. }\end{array}$ \\
& &
\end{tabular}

Fonte: CAPES. Elaborado pelos autores.

Um dos desafios para o aprimoramento das experiências da Pós-Graduação Profissional é o permanente cotejamento das propostas dos Programas com os aspectos mais gerais da árvore do conhecimento, em especial as duas áreas em 
questão (Teologia Prática e Ciência da Religião Aplicada) e as novas questões conceituais que têm desafiado as pesquisas. Essa é uma tarefa coletiva, a ser permanentemente realizada e que envolve os Programas e demais forças e fóruns que compõem a área. Tal avaliação, com as suas respectivas indicações de aprimoramento das práticas, deve ser feita em vários níveis, não se restringindo aos processos avaliativos formais e periódicos feitos pela Capes.

\subsection{O valor da produção técnica para a pós-graduação profissional}

Como já referido, as proposições de pós-graduação profissional precisam satisfazer as mesmas condições da pós-graduação acadêmica, sobretudo no que se refere à produção bibliográfica qualificada do corpo docente e discente, avaliada na publicação de artigos científicos em periódicos e de livros, e deve adicionalmente expressar uma definição bastante nítida do caráter profissional, valorizando especialmente a produção técnica.

Quanto à produção técnica na última avaliação quadrienal 2017, os programas profissionais demonstraram em dados quantitativos desempenhos distintos, ao menos quanto ao que se encontra registrado na Plataforma Sucupira. ${ }^{16}$ Naquele período, por falta de um instrumento de avaliação da produção técnica, não se realizou na área uma avaliação de natureza qualitativa. Espera-se que ao final do quadriênio 2017-2020 o uso do Qualis-TécnicoTecnológico possa dar maior consistência a esse processo tal como foi acordado pelos programas durante o Seminário de meio termo (CAPES, 2019c).

Nossa consideração é que a produção técnica, tanto de docentes quanto de discentes e de egressos, é fundamental para a pós-graduação profissional. Há uma série de produtos que devem ser valorizados pelos programas. O Documento orientador de APCN (CAPES, 2019b) orienta que haja evidente sinalização de que as produções técnicas, assim como as bibliográficas, "contribuem diretamente para

\footnotetext{
${ }^{16}$ Segundo dados a Avaliação Quadrienal 2017, disponíveis no Relatório da Avaliação (CAPES, 2017), a média da área foi de 661 itens na produção técnica. Esta mesma média, considerando apenas os três programas profissionais, foi de 739 itens.
} 
o desenvolvimento da pesquisa no curso e que possuem relação direta com a área (s) de concentração do curso, suas linhas, projetos de pesquisa e perfil do egresso”.

O mesmo se dá em relação à especificidade dos trabalhos de conclusão de curso (TCC). Na pós-graduação profissional esses trabalhos possuem natureza distinta. O Documento Orientador de APCN (CAPES, 2019b) traz uma relação que ajuda, não apenas aos proponentes de novos cursos, mas aos programas profissionais recomendados e reconhecidos da área, a nortear a produção desse importante trabalho.

No caso de trabalhos vinculados à inserção em ambientes socioeducativos, formais ou não formais, ONG, etc., deve-se dar prioridade a trabalhos que desenvolvam processos, projetos, técnicas ou produtos educativos ou formativos, aplicáveis a condições reais de sala de aula ou outros espaços de ensino ou inserção social atinentes à área. Esses produtos, projetos ou processos podem ser, considerados os conteúdos, métodos e técnicas próprios da área, por exemplo, sequência didática, material didático-pedagógico e instrucional, manuais, produção artística, modelo de gestão, aplicativo computacional, programas de mídia, jogo, vídeo, conjunto de videoaulas, equipamento, exposição, projeto (executado, concluído e avaliado) de extensão, projeto (executado, concluído e avaliado) de inserção social, consultorias/assessorias técnicas para organizações públicas/privadas, estudos de casos, e relatório técnico. O trabalho final deve (i) incluir necessariamente os componentes teórico-metodológicos que fundamentam o produto, projeto ou processo desenvolvido; (ii) incluir dados dos resultados do produto, projeto ou processo; (iii) incluir a análise, avaliação ou apreciação crítica concernente à aplicabilidade do produto, projeto ou processo desenvolvido, (iv) incluir anexos e referências. ${ }^{17}$

\footnotetext{
${ }^{17}$ Recomendamos consultar CAPES (2019b)
} 


\subsection{Potencialidades e limites da estrutura modular}

Os programas que atuam no mestrado profissional da área utilizam a estrutura modular para o cumprimento dos créditos curriculares, sendo que esses têm sido oferecidos de forma intensiva com aulas concentradas em duas quinzenas no início e outras duas no meio de cada ano. A carga horária de cada curso é cumprida integralmente nos dois períodos referidos. Essa dinâmica inovadora possibilita que os/as discentes atuem em suas atividades profissionais durante o transcorrer do ano e possam ajustar suas disponibilidades para cumprirem os créditos necessários em datas mais acessíveis. Também possibilita a participação de estudantes oriundos de diferentes regiões do País, na medida em que os cursos são concentrados em dois períodos anuais, facilitando viagens e deslocamentos.

Até o presente momento não há uma avaliação detalhada da parte da CAPES em relação à esta experiência de formação em nível de pós-graduação com o oferecimento de cursos intensivos e concentrados em períodos do ano. Há, de forma embrionária e, em certo sentido, intuitiva, a identificação de alguns aspectos que precisariam ser realçados visando o aprimoramento das práticas.

O primeiro é a mobilização de discentes de regiões geográficas diferentes, facilitada pela estrutura modular concentrada dos cursos. Ela possibilita o encontro e interações de pessoas com uma variedade de culturas e experiências que indiretamente enriquece a convivência acadêmica, tanto nas aulas quanto informalmente em espaços próximos de hospedagem. Esta estrutura favorece a captação de estudantes, o que contribui para melhor equacionamento financeiro das instituições que oferecem o curso com estas características. No caso dos mestrados profissionais, tal aspecto tem relevância na medida em que não há recursos governamentais para o oferecimento de bolsas de estudos para os/as discentes.

A presença dos/as estudantes em apenas dois períodos do ano no ambiente das instituições que oferecerem os cursos não favorece um número regular de encontros presenciais para orientação dos TCC. Esta lacuna é, em geral, suprida 
por encontros com o auxílio da Internet. O que está indicado, entre outros aspectos, é a necessidade de registros adequados dos encontros virtuais de orientação para oferecer maior visibilidade do processo efetivo de orientação.

A estrutura modular com aulas intensivas e concentradas também não favorece a participação dos/as estudantes em reuniões de grupos de pesquisa. É fato que tal atuação pode ser, a exemplo das orientações, suprida com a interação eletrônica. Isto também requer registros adequados para melhor visibilidade da integração dos/as estudantes em grupos de pesquisa.

O oferecimento dos cursos de forma intensiva e concentrada em poucos períodos do ano, ao atrair interessados/as que residem em localidades distantes da sede do curso, não favorece o uso da biblioteca da instituição. Isto pode ser suprido por várias formas, mas não pode ser confundido com o Ensino a Distância (EaD), que requer culturas, metodologias e instrumentos específicos. O mesmo se dá com as práticas de leituras regulares no interregno das aulas que, em geral, contribui para um processo progressivo de crescimento e maturidade acadêmica; o que não se dá devidamente com cursos intensivos.

Para o aprimoramento das experiências da pós-graduação profissional na área esses aspectos precisam ser acompanhados, percebidos em suas potencialidades e limitações, e refletidos. Outros aspectos precisam ser agregados, levando em conta as realidades de cada programa e da área como um todo.

\subsection{Perfil dos egressos}

Para fomentar a consolidação desse perfil interdisciplinar, a área tem recomendado, quanto à composição de seu corpo docente permanente, uma composição que seja diversa. Para os programas profissionais, considerando o perfil de egresso a ser formado, tanto mais se recomenda esta diversificação, podendo ser enriquecida com pesquisadores/as e profissionais de diversas outras áreas. Seria o caso de considerar, para a formação de profissionais que atuarão como teólogo/a ou cientista da religião no campo educacional, da capelania, da 
comunicação, da gestão de bens e patrimônios religiosos, da profissionalização das atividades religiosas, entre tantas possibilidades, que os programas profissionais avaliassem a pertinência de contar com profissionais de áreas como educação, ensino, comunicação, administração, sistemas de informação, serviço social, enfermagem, etc.

O perfil do egresso dos cursos da área prevê a formação de docentes para atuar, de forma aberta e plural, segundo um paradigma não confessional, com os conteúdos relacionados ao campo de estudos das religiões, das espiritualidades, das tradições religiosas, das tradições de sabedoria, do ateísmo, do agnosticismo e da não afiliação religiosa em ambientes escolares e públicos. Nesta direção, a área tem procurado incentivar os programas de pós-graduação a terem um aprofundado e qualificado intercâmbio com os cursos de graduação na área. Nesse sentido, a interface com o Ensino Religioso, no caso da Ciência da Religião Aplicada, e com a Pastoral escolar, no caso da Teologia Prática, se faz indispensável.

O Documento de área (CAPES, 2019a) expressa o perfil do/a pósgraduando/a na área: O documento traz uma caracterização geral, ou seja, comum aos programas da área que têm cursos reconhecidos e recomendados na modalidade acadêmica ou profissional ${ }^{18}$.

Quanto ao perfil para cursos de Teologia, com ênfase na subárea de Teologia prática, observa-se que a descrição tende a não reconhecer qualquer perspectiva de caráter proselitista ou apologético. O campo de atuação previsto é o profissional da teologia atuando na sociedade, o que inclui, obviamente, também a sua comunidade de fé específica.

Quanto ao perfil para cursos de Ciência(s) da(s) Religião(ões), o Documento de área (CAPES, 2019a) destaca o campo de atuação da docência, e/ou do trabalho especializado de consultoria, assessoria e mediação em questões relacionadas à

\footnotetext{
${ }^{18} \mathrm{Em}$ outros contextos profissionais deve-se estar atento para o fato de que a área Ciências da religião e Teologia não forma profissionais que não sejam o teólogo, a teóloga ou o/a cientista da religião. Por muito diversa que seja a procura de distintos profissionais por cursos da área, a finalidade da área será sempre formar o/a pós-graduado/a em Ciências da Religião e Teologia.
} 
religião no espaço público. Nesses casos, espera-se que um Programa Profissional nesse campo de atuação prepare os profissionais não apenas quanto aos saberes científicos, mas igualmente quanto aos saberes técnicos necessários para esse tipo de atuação.

\section{Considerações finais}

O processo de consolidação da pós-graduação profissional da área é um passo importante para um momento em que a ciência, de modo geral, procura enfrentar significativos desafios. A área de Ciências da Religião e Teologia, pelas suas características próprias, além de evidenciar sua importante inserção social, tem condições de colaborar com a formação de recursos humanos qualificados para o campo de estudos da religião no país. Programas profissionais se diferem dos programas acadêmicos por estarem voltados para a aplicação prática do conhecimento científico-acadêmico - o que também devem fazer com excelência.

Nos últimos cinco anos, desenvolveu-se um maior debate em torno do perfil dos programas profissionais da área Ciências da Religião e Teologia, através da enriquecedora participação ativa dos membros de seus programas. Esse tem sido um tempo de profundo crescimento para todos os envolvidos, sejam eles/elas docentes, discentes ou egressos/as. De nossa parte, ao apresentar esse conjunto de dados, avaliações e reflexões conceituais, procuramos oferecer elementos para o debate sobre a especificidade da pós-graduação profissional no âmbito da área Ciências da Religião e Teologia no Brasil. $\mathrm{O}$ aprimoramento das experiências nesta modalidade, à exemplo do conjunto dos esforços da área, requer a iniciativa e a participação de todos os segmentos envolvidos, desde os corpos docentes e discentes de cada programa, assim como suas coordenações e demais órgãos à eles ligados, incluindo a ANPTECRE e outros grupos afins.

A área vem demonstrando o seu empenho em produzir conhecimento qualificado e primar pela aplicação desses conhecimentos. Acredita-se que o processo de maior debate em torno do perfil dos programas profissionais da área 
com a elaboração colegiada de orientações mais claras para as atividades e rotinas previstas colaborará para que esta modalidade esteja ainda mais consolidada no país.

O objetivo principal das análises feitas foi construir um panorama de questões em torno do trabalho realizado pelos cursos de mestrados profissionais, incluindo os resultados por eles alcançados, somado a um elenco de aspectos que têm sido identificados como desafiadores para o aprofundamento e aprimoramento dessas práticas. As reflexões realçam a visão de uma prática profissional centrada em procedimentos e processos aplicados, visando a solução de problemas que emergem da realidade social.

Em um primeiro momento, apresentamos, em síntese, um histórico da pósgraduação profissional na área Ciências da Religião e Teologia, com destaque para o conjunto de motivações e objetivos que levaram o país a implementar a modalidade de programas profissionais no país. Em seguida, destacamos aspectos conceituais sobre a importância da pesquisa aplicada, em especial a tarefa de decolonização a ser desenvolvida no meio acadêmico, o debate em torno da árvore do conhecimento, especialmente as subáreas Ciência da Religião Aplicada e Teologia Prática e seus temas correlatos, o valor da produção técnica e a especificidade dos Trabalhos de Conclusão de Curso (TCC) para a pós-graduação profissional, as potencialidades e limites da estrutura modular para o oferecimento dos créditos curriculares e o perfil do egresso nesta modalidade. Como referido, esses elementos precisam ser ampliados e aprofundados pelos programas, pelos fóruns de acompanhamento e de avaliação e pelos demais setores e associações que interagem a área. Estamos conscientes de que se trata de uma tarefa inconclusa, permanente e que deve ser cumprida coletivamente. 


\section{REFERÊNCIAS}

AKOTIRENE, Carla. Interseccionalidade. São Paulo: Polén, 2019.

ALMEIDA, Silvio. Racismo estrutural. São Paulo: Pólen, 2019.

BERTH, Joice. Empoderamento. São Paulo: Polén, 2019.

CAMURÇA, Marcelo. Ciências Sociais e Ciências da Religião. Polêmicas e interlocuções. São Paulo: Paulinas, 2008.

CAPES - COORDENAÇÃO DE APERFEIÇOAMENTO DE PESSOAL DE NÍVEL SUPERIOR. Portaria 174, de 11 de outubro de 2016. Diário Oficial da União, Brasília, 13 out. 2016.

CAPES - COORDENAÇÃO DE APERFEIÇOAMENTO DE PESSOAL DE NÍVEL SUPERIOR. Resolução no ${ }^{0}$, de 4 de abril de 2017. Boletim de Serviço/CAPES, Brasília, Edição Especial n ${ }^{0}$ 1, abr. 2017a.

CAPES - COORDENAÇÃO DE APERFEIÇOAMENTO DE PESSOAL DE NÍVEL SUPERIOR. Documento de área. Área Ciências da Religião e Teologia. Brasília, 1 jul. 2019a. Disponível em: https://www.capes.gov.br/avaliacao/sobre-as-areas-deavaliacao/74-dav/caa2/4643-teologia Acesso em: 11 maio 2020.

CAPES - COORDENAÇÃO DE APERFEIÇOAMENTO DE PESSOAL DE NÍVEL SUPERIOR. Relatório de avaliação. Área Ciências da Religião e Teologia. Brasília, 20 set. 2017. Disponível em: https://www.capes.gov.br/avaliacao/sobre-as-areas-deavaliacao/74-dav/caa2/4643-teologia Acesso em: 11 maio 2020.

CAPES - COORDENAÇÃO DE APERFEIÇOAMENTO DE PESSOAL DE NÍVEL SUPERIOR. Documento Orientador de APCN. Área Ciências da Religião e Teologia. Brasília, 15 de julho de 2019b. Disponível em: https://www.capes.gov.br/avaliacao/sobreas-areas-de-avaliacao/74-dav/caa2/4643-teologia Acesso em: 11 maio 2020.

CAPES - COORDENAÇÃO DE APERFEIÇOAMENTO DE PESSOAL DE NÍVEL SUPERIOR. Relatório do Seminário de Meio Termo. Área Ciências da Religião e Teologia. Brasília, 25 de outubro de 2019c. Disponível em: https://www.capes.gov.br/avaliacao/sobre-as-areas-de-avaliacao/74-dav/caa2/4643teologia Acesso em: 11 maio 2020.

CARNEIRO, Aparecida Sueli. A construção do outro como não-ser como fundamento do ser. 2005. Tese (Doutorado em Educação) - Programa de PósGraduação em Educação da Universidade de São Paulo, 2005.

COSTA, Matheus Oliva da. Ciência da religião aplicada como o terceiro ramo da Religionswissenschaft: História, análises e propostas de atuação profissional. Tese (Doutorado cm Ciência da Religião) - Programa de Estudos Pós-Graduados em Ciência da Religião da PUC-SP, São Paulo, 2019.

DAVIS, Angela. Mulheres, raça e classe. São Paulo: Boitempo, 2016. 
FERREIRA, Amauri Carlos; SENRA, Flávio. Tendência interdisciplinar das Ciências da Religião no Brasil. O debate epistemológico em torno da interdisciplinaridade e o paralelo com a constituição da área no país. Numen, Juiz de Fora, v. 15, n. 2, jul./dez. 2012.

FLOR DO NASCIMENTO, Wanderson. Intolerância ou racismo? Jornal Hora Grande, Porto Alegre, outubro de 2016, ano XXI, edição 167, p. 15. Disponível em: https://www.academia.edu/31433487/Intoler\%C3\%A2ncia_ou_racismo? Acesso em: 15 maio 2020.

FLOR DO NASCIMENTO, Wanderson. O fenômeno do racismo religioso: desafios para os povos tradicionais de matrizes africanas. Revista Eixo, Brasília, v. 6, n. 2, maio/ago. 2017.

HANEGRAAFF, Wouter Jacobus. Definindo religião, apesar da história. Tradução de Fábio Leandro Stern. Religare, Paraíba, v. 14, n. 1, jan./jun. 2017.

MEC - MINISTÉRIO DA EDUCAÇÃO. Portaria nº 389, de 23 de março de 2017. Diário Oficial da União, Brasília, 23 mar. 2017.

MEC - MINISTÉRIO DA EDUCAÇÃO. Portaria Normativa $n^{0}$ 17, de 28 de dezembro de 2009. Diário Oficial da União, Brasília, 29 dez. 2009 b.

MEC - MINISTÉRIO DA EDUCAÇÃO. Portaria Normativa $\mathrm{n}^{0}$ 7, de 22 de junho de 2009. Diário Oficial da União, Brasília, 23 jun. $2009 a$.

MESQUIATTI, David \& BROTTO, Julio Cesar de Paula. O trabalho de Conclusão de Curso (TCC) no Mestrado Profissional (MP): um estudo de caso do MP em Ciências das Religiões da Faculdade Unida (UNIDA). Estudos de Religião, São Paulo, v. 32, n. 1, jan./abr. 2018.

MINISTÉRIO DA JUSTIÇA E CIDADANIA. Relatório sobre intolerância e violência religiosa no Brasil (2011-2015): resultados preliminares; organização, Alexandre Brasil Fonseca, Clara Jane Adad. - Brasília: Secretaria Especial de Direitos Humanos, SDH/PR, 2016.

MINISTÉRIO DA MULHER, DA FAMÍLIA E DOS DIREITOS HUMANOS - DISQUE 100. Balanço Geral 2011 ao 10 semestre de 2019 - Discriminação Religiosa, 2019. Disponível em: https://www.gov.br/mdh/pt-br/acesso-a-informacao/ouvidoria/balancodisque-100. Acesso em: 03 maio de 2020.

MIRANDA, Ana Paula Mendes de. Como se discute Religião e Política? Controvérsias em torno da luta contra a intolerância religiosa no Rio de Janeiro. Comunicações do ISER, Rio de Janeiro, v. 69, p. 10-23, 2014. Disponível em:

http://www.iser.org.br/site/comunicacoes-iser/. Acesso em: 15 maio 2020.

MIRANDA, Ana Paula Mendes de; CORREA, Roberta de Mello; ALMEIDA, Rosiane Rodrigues de. Intolerância religiosa: a construção de um problema público. Revista Intolerância Religiosa - Koinonia, Rio de Janeiro, v. 1, n. 2, jul./dez 2017. 
NUNES, João Arriscado. O resgate da epistemologia. In: SANTOS, Boaventura de Souza; MENESES, Maria Paula (org.). Epistemologias do Sul. São Paulo: Cortez Editora, 2010. p. 261- 290.

PHILIPPI JÚNIOR, Arlindo; SILVA NETO, Antônio (org.). Interdisciplinaridade em ciência, tecnologia \& inovação. Barueri: Manole, 2011.

RIBEIRO, Claudio de Oliveira. O princípio pluralista como elemento articulador de pesquisas na área Ciências da Religião e Teologia. Rever, São Paulo, v. 19, n. 2, maio/ago. 2019.

RIBEIRO, Claudio de Oliveira. Testemunho e Libertação: a Teologia Latino-Americana em Questão. São Paulo: Fonte Editorial, 2016.

ROCHA, Abdruschin Schaeffer; RIBEIRO, Osvaldo Luiz. Ciência(s) da Religião Aplicada(s): uma contribuição do mestrado profissional em ciências das religiões da Faculdade Unida de Vitória. Rever, São Paulo, v. 19, n. 2, maio/ago. 2019.

SAMPAIO, Dilaine Soares. Ciências da Religião e Teologia como área autônoma: reconfiguração do debate epistemológico, novos desafios e perspectivas para o estudo das (não) religiões e da(s) espiritualidade(s). Horizonte, Belo Horizonte, v. 17, n. 53, maio/ago. 2019.

SANTOS, Boaventura de Souza; MENESES, Maria Paula (org.). Epistemologias do Sul. São Paulo: Cortez Editora, 2010.

SENRA, Flávio. Estudos de Ciência(s) da(s) Religião(ões) e Teologia no Brasil: Situação atual e perspectivas. Rever, São Paulo, v. 15, n. 2, maio/ago. 2015.

SENRA, Flávio. O teólogo e o cientista da religião: Religiografia acerta das interfaces entre Ciências da Religião e Teologia no Brasil. Rever, São Paulo, v. 16, n. 1, jan./abr. 2016.

SENRA, Flávio. Programas profissionais. Situação atual e perspectivas na área Ciências da Religião e Teologia no Brasil. Reflexus, Vitória, v. 11, n. 18, jul./dez. 2017.

SENRA, Flávio; CAMPOS, Fabiano Victor; ALMEIDA, Tatiane. (org.). Epistemologia das Ciências da Religião. Curitiba, Editora CRV, 2020.

STERN, Fábio Leandro; COSTA, Matheus Oliva da (org.) Ciência da Religião Aplicada: ensaios pela autonomia e aplicação profissional [recurso eletrônico] / Fábio Leandro. Porto Alegre, Editora Fi, 2018. Disponível em: https://www.editorafi.org/506religiao. Acesso em: 15 maio 2020.

STRECK, Gisela; ALMEIDA, Thiago. Mestrado Profissional em Teologia da Faculdades EST: Panorama histórico e atuação profissional de egressos e egressas. Estudos

Teológicos, São Leopoldo, v. 57, n. 1, jan./jun 2017.

TEIXEIRA, Faustino. Ciência da Religião e Teologia. In: PASSOS, João Décio; USARSKI, Frank (org.). Compêndio de Ciência da Religião. São Paulo: Paulinas: Paulus, 2013. 
TWORUSCHKA, Udo. Ciência Prática da Religião: considerações teóricas e metodológicas. In: USARSKI, Frank. PASSOS, João Décio. Compêndio de Ciência da Religião. São Paulo: Paulinas: Paulus, 2013.

TWORUSCHKA, Udo. Considerações sobre a ciência prática da religião. In: STERN, Fábio L.; COSTA, Matheus Oliva da (org.) Ciência da Religião Aplicada: ensaios pela autonomia e aplicação profissional [recurso eletrônico] / Fábio Leandro. Porto Alegre: Editora Fi, 2018. Disponível em: https://www.editorafi.org/506religiao. Acesso em: 15 maio 2020.

VILLAS BOAS, Alex. Introdução à epistemologia do fenômeno religioso interface entre ciências da religião e teologia. Curitiba: Editora Intersaberes, 2020.

VILLAS BOAS, Alex. Perspectiva interdisciplinar da teologia no Brasil: O. debate epistemológico da Área de Ciências da Religião e Teologia. Interações, v. 13, n. 24, ago./dez. 2018.

VON SINNER, Rudolf. Teologia pública no Brasil um primeiro balanço. Perspectiva Teológica, v. 44, n. 122, maio/ago. 2012.

WIRTH, Lauri Emílio. Religião e epistemologias pós-coloniais. In: PASSOS, João Décio. USARSKI, Frank. Compêndio de Ciência da Religião. São Paulo: Paulinas, Paulus, 2013. p. 129-142. 